\title{
An Interesting Neonatal Presentation
}

\section{Maha Hassan Mohamed ${ }^{\star}$}

Ain Shams University Faculty of Medicine, Cairo, Cairo Egypt

\begin{abstract}
We present a 1 week old female new-born with extensive subcutaneous fat necrosis. Due to extensive necrosis, excision and skin grafting was done.
\end{abstract}

Keywords: Swelling; Subcutaneous; Fat; Necrosis; Hypercalcemia; New-born

\section{Case Report}

Our case was a full term female, 38 weeks of gestation, 7 days old, delivered by caesarean section after an attempt of vaginal delivery, $1^{\text {st }}$ order of birth of non-consanguineous parents of low average socioeconomic class. She was presented with multiple swellings on the back, buttocks, left arm of one day duration, with rapid onset and progressive course. No maternal history of gestational diabetes or preeclampsia, with proper antenatal care. Patient was admitted to another NICU during the first $72 \mathrm{~h}$ of life due to respiratory distress diagnosed as transient tachypnea of the newborn. No history of trauma. No family history of similar condition, no history of diabetes, hypertension or blood diseases.

By examination; she was $3.8 \mathrm{~kg}$ in weight, $50 \mathrm{~cm}$ in length, with occipitofrontal circumference of $38 \mathrm{~cm}$, anterior fontanel $5 \times 5 \mathrm{~cm}$, full. Her pulse was $170 / \mathrm{min}$, regular with normal capillary refill time, blood pressure was $65 / 40$, respiratory rate was $40 \mathrm{breath} / \mathrm{min}$ and temperature was $37.4^{\circ} \mathrm{C}$. She was pale, with no jaundice, no cyanosis. Liver was $3 \mathrm{~cm}$ below costal margin, soft, not tender, rounded border, no splenomegaly. Chest and cardiac examination showed no abnormality. She had multiple huge swellings overlying back of left arm, back and gluteal region, purplish, mildly tender, firm with overlying edema at the periphery, with areas of necrosis (Figures 1 and 2).

Her blood count showed leucocytosis, total leukocytic count: $22.8 \times$ $10^{3} / \mathrm{cm}^{3}$, hemoglobin: $6.5 \mathrm{~g} \%$, platelet count: $128 \times 10^{3} / \mathrm{cm}^{3}$, C-reactive protein: $160 \mathrm{mg} / \mathrm{dl}$, Prothrombin time: $18.5 \mathrm{~s}$, Partial thromboplastin time: 70 s, INR: 1.6 , fibrin degradation products: $15 \mathrm{mcg} / \mathrm{ml}(>40 \mathrm{mcg} /$ $\mathrm{ml}$ indicates disseminated intravascular coagulopathy) and normal total and ionized serum calcium. Normal Protein C, S, anti-thrombin III assay. Initial blood culture and skin swabs showed no growth of organisms.

Differential diagnosis was considered; haemangioma, vascular malformation (kaposiform hemangioendothelioma or tufted angioma), hematoma, necrotizing fasciitis, purpura fulminans and subcutaneous fat necrosis.

CT brain was done for her and showed hyper dense material occupying brain sulci, basal cisterns and lateral and fourth ventricle mostly subarachnoid and intraventricular hemorrhage with dilatation in the ventricular system. Abdominal ultrasonography showed mild hepatomegaly with no focal lesions, other findings showed no abnormalities. Duplex ultrasonography detected no vascular lesions with no arterial, venous or mixed blood flow excluding the diagnosis of hemangioma or vascular anomaly. The presented lesion was likely to be cutaneous or subcutaneous tissue lesion which could be inflammatory.

Skin biopsy was consistent with subcutaneous fat necrosis with a dense inflammatory infiltrate composed of lymphocytes, histiocytes and multinucleated giant cells. Some lipocytes were replaced by radially arranged needle-shaped clefts.

On the $13^{\text {th }}$ day of life, the lesions of the back became fluctuant with a spontaneous drainage revealing a chalky non-purulent substance. Due to extensive involvement, excision with skin grafting was done. In addition, ventriculo-peritoneal shunt was inserted. That was the reason why serial follow up of the patient did not show hypercalcemia afterwards (Figure 3).

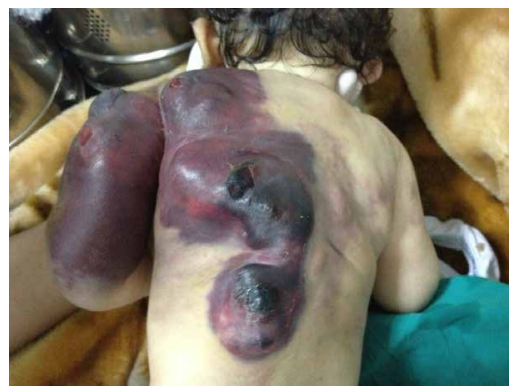

Figure 1: Firm purplish nodules on the back and back of left arm with areas of superficial necrosis.

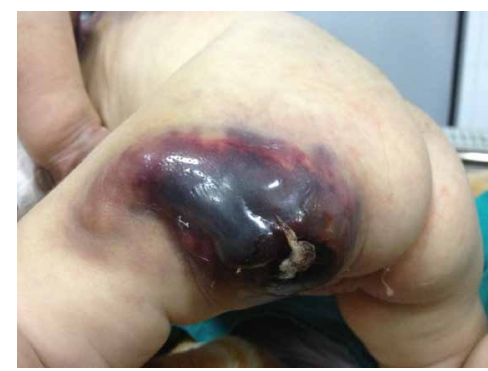

Figure 2: Firm purplish nodules on the left buttock with areas of superficial necrosis.

*Corresponding author: Maha Hassan Mohamed, Ain Shams University Faculty of Medicine, Cairo, Cairo, Egypt, Tel: 002-01005287175; E-mail: dr_mhassan21@yahoo.com

Received October 15, 2016; Accepted November 17, 2016; Published November 23, 2016

Citation: Mohamed MH (2016) An Interesting Neonatal Presentation. J Neonatal Biol 5: 239. doi: 10.4172/2167-0897.1000239

Copyright: ๑ 2016 Mohamed MH. This is an open-access article distributed under the terms of the Creative Commons Attribution License, which permits unrestricted use, distribution, and reproduction in any medium, provided the original author and source are credited. 


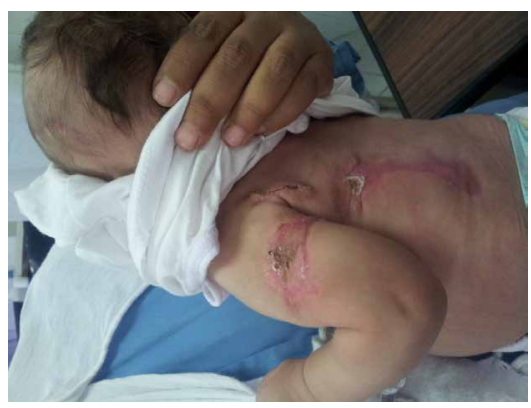

Figure 3: Two weeks after surgery.

\section{Subcutaneous Fat Necrosis}

Subcutaneous fat necrosis is a rare, temporary, self-limited pathology affecting adipose tissue of full-term or post-term neonates. It is a form of panniculitis [1]. Although exact pathogenesis is not clear, it is postulated that cold or stress-induced injury to immature fat cells results in the development of solidification and necrosis with formation of granulomatous tissue [2]. Suggested etiologies include fetal factors such as a primary defect in subcutaneous fat, perinatal complications (especially ischemic injury), local trauma, hypothermia or birth hypoxia, maternal disorders such as gestational diabetes, preeclampsia, or maternal exposure to cocaine or calcium antagonists [1]. For our patient the triggering factor could have been the decreased tissue perfusion from first days of hypoxia.

It is characterized by firm, mobile, discrete erythematous to purplish nodules and plaques over the trunk, arms, buttocks, thighs, and cheeks of full-term new-borns [3]. It is a benign condition that does not require treatment. Skin lesions typically resolve over a period of weeks to several months. Patients should be followed for up to 6 months after the appearance of the skin lesions to detect manifestations of hypercalcemia [2]. In addition, patients should be evaluated and monitored for hypoglycemia, hypertriglyceridemia, anemia, thrombocytopenia [4]. The most important concern is hypercalcemia, which can lead to neurologic or cardiac problems, nephrocalcinosis and nephrolithiasis. Clinical signs of neonatal hypercalcemia include irritability, poor feeding and vomiting. Staining of biopsy specimens demonstrates increased levels of 1 alpha-hydroxylase within the granulomatous infiltrate. Alpha-hydroxylase promotes the conversion of $25 \mathrm{OH}$ D3 to its active form $1,25 \mathrm{OH}_{2} \mathrm{D} 3$. The treatment of hypercalcemia ranges from conservative measures such as hydration and restriction of vitamin D and calcium to more aggressive interventions such as furosemide, glucocorticoid or bisphosphonate therapy [5].

\section{References}

1. Mahé E, Girszyn N, Hadj-Rabia S, Bodemer C, Hamel-Teillac D, et al. (2007) Subcutaneous fat necrosis of the newborn: A systematic evaluation of risk factors, clinical manifestations, complications and outcome of 16 children. $\mathrm{Br}$ J Dermatol 156: 709-715

2. Grewal SK (2016) Subcutaneous fat necrosis of newborn.

3. Dudink J, Walther FJ, Beekman RP (2003) Subcutaneous fat necrosis of the newborn: Hypercalcaemia with hepatic and atrial myocardial calcification. Arch Dis Child Fetal Neonatal Ed 88: F343-F345.

4. Tran JT, Sheth AP (2003) Complications of subcutaneous fat necrosis of the new-born: A case report and review of literature. Pediatr Dermatol 20: 257-261.

5. Farooque A, Moss C, Zehnder D, Hewison M, Shaw NJ (2009) Expression of 25-hydroxyvitamin D3-1alpha-hydroxylase in subcutaneous fat necrosis. $\mathrm{Br} \mathrm{J}$ Dermatol 160: 423-425. 